\title{
Níveis plasmáticos de vitamina $D$ em crianças e adolescentes com colestase
}

\author{
Blood levels of vitamin D in children and adolescents with chronic cholestasis
}

\author{
Marília D. Bastos ${ }^{1}$, Themis R. da Silveira ${ }^{2}$
}

\section{Resumo}

Objetivo: verificar os níveis plasmáticos de vitamina D de pacientes colestáticos crônicos e relacionar com estado nutricional, tempo de colestase e uso de suplemento vitamínico.

Métodos: estudo transversal controlado, cujo fator em estudo é colestase crônica e o desfecho, o nível plasmático de vitamina D. Pacientes entre quatro meses a 18 anos, atendidos na unidade de gastroenterologia pediátrica do HCPA; como controles, crianças eutróficas da mesma faixa etária. Foi coletado sangue para as dosagens por radioimunoensaio, e realizadas avaliação antropométrica, pesquisa de tempo de colestase e uso de suplemento vitamínico.

Resultados: foram avaliadas 22 crianças e adolescentes com colestase crônica e 17 controles. O valor médio de vitamina $D$ entre os pacientes foi de $13,7 \pm 8,39 \mathrm{ng} / \mathrm{ml}$, enquanto que nos controles foi de $25,58 \pm 16,73 \mathrm{ng} / \mathrm{ml}(\mathrm{p}=0,007)$. A prevalência de hipovitaminose $\mathrm{D}$, entre os pacientes, foi de $36 \%$. A mediana do tempo de colestase foi de um ano. A avaliação antropométrica (NCHS) demonstrou $36 \%$ de desnutrição pelo peso, e $41 \%$ para estatura. Na avaliação antropométrica pelo escore z, obtivemos prevalência de desnutrição para os critérios altura/idade e peso/idade de $33,3 \%$ e $23,8 \%$, respectivamente. Avaliado peso em relação altura, não observamos valores abaixo de dois desvios padrão. Não foi observada relação entre o estado nutricional, o uso de suplemento oral e os níveis plasmáticos de vitamina $\mathrm{D}$

Conclusões: os níveis plasmáticos de vitamina $\mathrm{D}$ em colestáticos foram menores do que os dos controles, sem relação com estado nutricional, tempo de colestase e/ou uso suplementação vitamínica.

J Pediatr (Rio J) 2003;79(3):245-52: colestase crônica,vitamina $\mathrm{D}$, desnutrição.

1. Mestre em Pediatria - Univ. Federal do Rio Grande do Sul (UFRGS).

2. Prof. Adjunta Doutora do Dep. de Pediatria da Faculdade de Medicina da UFRGS. Mestre e Doutora. Coordenadora do Programa de Transplante Hepático Infantil do Hospital de Clínicas de Porto Alegre (HCPA).

Fonte financiadora: Fundo de Incentivo à Pesquisa do HCPA.

Artigo submetido em 01.11.02, aceito em 04.02.03.

\begin{abstract}
Objective: to verify blood levels of vitamin $\mathrm{D}$ in patients with chronic cholestasis, and relate them to nutritional status, length of time since the onset of cholestasis and use of vitamin supplement.

Methods: controlled cross-sectional study with chronic cholestasis as study factor and blood levels of vitamin $\mathrm{D}$ as outcome. The study included patients aged between 4 months and 18 years, who were cared for at the Pediatric Gastroenterology Unit of Hospital de Clínicas de Porto Alegre. Controls were eutrophic children in the same age range. Blood was collected for radioimmunoassay. Anthropometric analyses were performed, as was determination of the length of time since the onset of cholestasis and use of vitamin supplement.
\end{abstract}

Results: twenty-two patients and 17 controls were evaluated. Average vitamin D level in patients was $13.7 \pm 8.39 \mathrm{ng} / \mathrm{ml}$, compared to $25.58 \pm 16.73 \mathrm{ng} / \mathrm{ml}$ in controls $(\mathrm{p}=0.007)$. Prevalence of hypovitaminosis D in patients was $36 \%$. Median of period of time since the onset of cholestasis was 1 year with variation of 6 months to the 25th percentile and 3.9 years to the 75 th percentile. Anthropometric evaluation (NCHS) showed $36 \%$ of malnutrition by weight and $41 \%$ by height. Anthropometric evaluation according to $\mathrm{Z}$ score showed $33.3 \%$ and $23.8 \%$ prevalence of malnutrition for the criteria height/age and weight/age, respectively. The evaluation of weight regarding height did not show values below two standard deviations. No relationship was found between nutritional state, use of oral vitamin supplement and blood levels of vitamin D.

Conclusions: blood levels of vitamin D in patients with cholestasis were lower than those of controls, but were not related to nutritional status, period of time since the onset of cholestasis or use of vitamin supplement.

JPediatr (Rio J) 2003;79(3):245-52: chronic cholestasis, vitamin $\mathrm{D}$, malnutrition.

\section{Introdução}

Colestase é a redução ou ausência de fluxo biliar no duodeno, que pode resultar de falha do hepatócito em secretar bile, da ausência de ductos biliares intra-hepáticos ou da obstrução dos ductos extra-hepáticos ${ }^{1}$. 
O estado nutricional de uma criança com doença hepática crônica é um dos fatores que interferem na sobrevida, tanto dos pacientes que aguardam um transplante como daqueles que já o fizeram ${ }^{2,3}$.

A ausência de bile no intestino causa esteatorréia, com os sinais e sintomas decorrentes de má absorção, que são ${ }^{4}$ diarréia, desnutrição, redução das proteínas plasmáticas, cegueira noturna e lesões de pele, devido à absorção deficiente de vitamina $\mathrm{A}$; osteopenia, devido à má absorção de vitamina $\mathrm{D}$; sangramentos e hematomas decorrentes da má absorção de vitamina K; e enfraquecimento neuromuscular decorrente da má absorção de vitamina $\mathrm{E}$.

As vitaminas lipossolúveis compreendem as vitaminas A, D, E e K. São absorvidas no trato gastrintestinal, juntamente com as gorduras da dieta. $\mathrm{O}$ organismo não é capaz de sintetizá-las, ou sintetiza em quantidades insuficientes, necessitando ser fornecidas pelos alimentos.

Considerando a sua disponibilidade, metabolismo e mecanismo de ação, é mais correto considerar a vitamina $D$ um hormônio esteróide do que uma vitamina no sentido clássico. Esta vitamina ocorre naturalmente em alimentos de origem animal, na forma de colecalciferol. É encontrada em quantidades pequenas e altamente variáveis na manteiga, na nata, na gema de ovo e fígado. O óleo de fígado de peixes é considerado a melhor fonte de vitamina $\mathrm{D}$, e foi reconhecida historicamente como a forma de cura para o raquitismo ${ }^{5}$.

Os pacientes com colestase crônica apresentam má absorção da vitamina $\mathrm{D}$ da dieta associada à menor exposição solar, decorrentes do estado patológico em si. As manifestações primárias da deficiência de vitamina $\mathrm{D}$ são hipocalcemia, hipofosfatemia, tetania, osteomalácia e raquitismo ${ }^{2}$.

A habilidade de medir com precisão os metabólitos da vitamina D no soro ou plasma humano tem sido aperfeiçoada nas últimas décadas, mas, apesar deste progresso, somente as medidas de $25 \mathrm{OHD}$ e 1,25 $\left(\mathrm{OH}_{2}\right) \mathrm{D}$ têm sido clinicamente úteis ${ }^{6}$. A dosagem de $25 \mathrm{OHD}$ é a forma mais apropriada de se verificar a real situação dos níveis plasmáticos de vitamina $\mathrm{D}$, uma vez que os níveis de 1,25 $\left(\mathrm{OH}_{2}\right)$ D são mais indicativos da situação do cálcio, e não seriam essenciais para a monitorização da vitamina $\mathrm{D}^{7}$.

As formas de dosar 25 OHD descritas na literatura são: Competitive Protein Binding Assay (CPBA), High-Pressure Liquid Cromatography (HPLC) e radioimunoensaio (RIE). As técnicas por CBPA e HPLC necessitam de desproteinização ou extração, assim como a preparação cromatográfica, que necessita de um volume grande da amostra (1 a $5 \mathrm{ml}$ ). São técnicas consideradas trabalhosas e de alto custo ${ }^{8}$. Até alguns anos, os autores consideravam a técnica por radioimunoensaio pouco específica, e necessitava de purificação cromatográfica prévia ${ }^{6}$. Estudos mais recentes utilizam anti-soros, que permitem realizar dosagens com maior especificidade e simplicidade na execução, sem necessitar maior volume de plasma ou soro ${ }^{9}$.
A deficiência de vitamina $\mathrm{D}$, segundo estudos de Heubi e colaboradores ${ }^{10}$, não parece ser a causa principal da osteopenia na colestase crônica. Admitem que a combinação de alterações na absorção mineral e de vitamina D, associada a alterações na matriz protéica, deve contribuir para a doença óssea metabólica nestes pacientes. Tem-se observado que pacientes com colestase crônica que normalizam seu status de vitamina D podem continuar com evidência de doença óssea metabólica, e isto reforça a idéia de haver outros fatores que contribuem para a osteopenia nestes pacientes ${ }^{2}$.

A verificação dos níveis plasmáticos de vitamina $D$ não é realizada rotineiramente. Não foram encontrados estudos brasileiros sobre hipovitaminose $\mathrm{D}$ em crianças com hepatopatia, mas a deficiência de mineralização óssea em crianças com colestase crônica, avaliada por densitometria, já é conhecida no nosso meio ${ }^{11}$.

Este estudo tem com objetivo verificar os níveis plasmáticos de vitaminas D de uma amostra de crianças e adolescentes com colestase crônica, e relacionar com o estado nutricional, tempo de colestase e uso de suplemento vitamínico.

\section{Métodos}

Foi realizado um estudo transversal controlado, cujo fator em estudo foi colestase crônica, e o desfecho é o nível plasmático de vitamina $\mathrm{D}$. A população estudada constou de crianças e adolescentes colestáticos, que consultaram no ambulatório, ou estiveram internados na unidade de gastroenterologia pediátrica do Hospital de Clínicas de Porto Alegre (HCPA), no período de dezembro de 2000 a abril de 2002. Participaram, como controles, crianças e adolescentes eutróficos e normais, do ponto de vista gastrenterológico, que consultaram no ambulatório de cirurgia pediátrica do HCPA, para realização de cirurgia eletiva durante o mesmo período.

Os critérios utilizados para inclusão dos pacientes foram os seguintes:

- faixa etária de quatro meses a 18 anos;

- evidência de colestase por período superior a três meses, diagnosticada através de icterícia, colúria, acolia ou prurido, devido à hiperbilirrubinemia de reação direta, superior a $30 \%$ da bilirrubina total.

Os critérios de exclusão dos pacientes foram os seguintes:

- hepatopatia crônica sem evidência de colestase;

- uso de vitamina D injetável nos últimos 30 dias;

- uso de nutrição parenteral total (NPT) nos últimos três meses;

- não assinatura do termo de consentimento informado pelos responsáveis. 
Os critérios de inclusão para os controles foram os seguintes:

- mesma faixa etária dos pacientes avaliados (quatro meses a 18 anos);

- peso e estatura entre os percentis 25 e 75 para idade e sexo, a partir do gráfico de crescimento do National Center of Healh Statistics (NCHS).

Os critérios de exclusão dos controles foram os seguites:

- evidência de doença hepática ou gastrintestinal, verificada através da história, exame físico e revisão do prontuário;

- não assinatura do termo de consentimento informado pelos responsáveis.

O tamanho da amostra foi calculado para um poder estatístico de $80 \%$, considerando um $\alpha=0,05$ e um tamanho de efeito de aproximadamente um desvio padrão. Para isto, foi necessária a inclusão de, no mínimo, 34 indivíduos entre casos e controles.

Após o consentimento dos familiares, foi coletado sangue para proceder as dosagens da vitamina D. O sangue era coletado e colocado em frasco com EDTA e, após centrifugação, o plasma era armazenado no freezer a $-80^{\circ} \mathrm{C}$, para posterior dosagem da vitamina. Para os controles, além dos exames pré-operatórios que deveriam realizar, era solicitada autorização dos pais para coletar uma amostra de sangue para a dosagem da vitamina. A técnica utilizada para dosagem plasmática da referida vitamina foi a de radioimunoensaio com o kit 25-hidroxyvitamin D-Nichols Institute Diagnostics - Paris.

No momento da coleta de sangue, foi realizada a avaliação nutricional dos pacientes colestáticos. A análise dos resultados antropométricos foi feita a partir das tabelas do $(\mathrm{NCHS})^{12}$ para os percentis e escore $\mathrm{z}^{13}$. Foram considerados desnutridos os indivíduos com medidas de peso e estatura com dois ou mais desvios padrão abaixo da média pelo escore z, ou percentil menor que cinco nos padrões de NCHS

Foi verificada, através de questionário, a utilização do suplemento de vitaminas lipossolúveis que é prescrito aos colestáticos, que consta de Aderogil D3 ${ }^{\circledR}, 12$ gotas, duas vezes ao dia (vitamina A $6.600 \mathrm{UI} / \mathrm{dl}$ e vitamina D 2.600 $\mathrm{UI} / \mathrm{dl}$ ); Ephynal ${ }^{\circledR}, 400 \mathrm{mg}$ a cada quatro dias (vitamina E $100 \mathrm{mg} /$ dia); e Kanakion ${ }^{\circledR}$, uma vez por mês (vitamina K, $5 \mathrm{mg} / \mathrm{mês})$.

O tempo de colestase era definido pela data do diagnóstico da doença de base, identificada pela história clínica, e revisão do prontuário do paciente.

O projeto de pesquisa Níveis séricos de vitamina $D$ em crianças e adolescentes com colestase crônica foi aprovado pela Comissão de Pesquisa e Ética em Saúde do HCPA, juntamente com o protocolo de entrevista e os termos de consentimento dos pacientes e controles.
O programa estatístico utilizado foi o Statistical Package for Social Science (SPSS). Foi realizada análise descritiva, para caracterizar a população estudada com percentual média, mediana, desvio padrão e percentis.

O teste $t$ paramétrico foi utilizado para avaliar os resultados com comportamento normal entre os dois grupos (colestáticos e controles): idade e nível plasmático de vitamina $\mathrm{D}$. Os demais testes estatísticos foram não paramétricos, por não haver uma distribuição normal das variáveis de interesse. $\mathrm{O}$ teste de qui-quadrado foi utilizado para as comparações entre variáveis qualitativas de gênero, grupo, avaliação nutricional e uso de suplementação oral, e o teste U de Mann-Whitney para as variáveis quantitativas (idade, níveis plasmáticos, tempo de colestase). As correlações entre níveis plasmáticos com o tempo de colestase foram analisadas pelo coeficiente de Spearman. Em todos os testes citados, foram considerados como significativos um valor de $\mathrm{p}<0,05$.

\section{Resultados}

Participaram do estudo 22 crianças e adolescentes com colestase crônica, sendo 13 do sexo feminino $(59,1 \%)$, e 9 do sexo masculino (40,9\%). A mediana de idade foi 3,6 anos, com variações entre 10 meses para o percentil 25 , e 12 anos para o percentil 75. Participaram como controles 17 crianças normais, sendo 13 do sexo masculino (76,5\%), e quatro do sexo feminino $(23,5 \%)$. A mediana de idade foi 4,3 anos, com variações entre dois anos para o percentil 25 , e 10,8 anos para o percentil 75 . Não houve diferença estatística entre os colestáticos e o grupo controle para idade $(\mathrm{p}=0,235)$ ou gênero $(\mathrm{p}=0,42)$.

$\mathrm{Na}$ Tabela 1, verificamos as características clínicolaboratoriais de cada paciente estudado. Na avaliação antropométrica pelas tabelas do NCHS, observamos uma prevalência de $36 \%$ de desnutrição pelo peso, e $41 \%$ para estatura, em relação à idade e ao sexo. Na avaliação antropométrica pelo escore $\mathrm{z}$, obtivemos uma prevalência de desnutridos para os critérios altura/idade e peso/idade de $33,3 \%$ e $23,8 \%$, respectivamente. Quando avaliado o peso em relação altura, não observamos valores abaixo de dois desvios padrão.

O uso regular de suplemento oral de vitaminas lipossolúveis foi observado em 14 pacientes (63\%). Os oito pacientes restantes $(36,4 \%)$ não faziam uso, ou usavam de modo irregular a medicação prescrita.

A mediana do tempo de colestase foi um ano, com variações entre seis meses para o percentil 25, e 3,9 anos para o percentil 75. Ao relacionar o tempo de colestase com o estado nutricional a partir do escore $\mathrm{z}(\mathrm{A} / \mathrm{I})$, observamos que os pacientes eutróficos têm um período de colestase que varia de três meses a 7,7 anos, com uma mediana de seis meses; já os desnutridos têm um período de colestase que varia de quatro meses a 16 anos, com uma mediana de 12 meses. Estas diferenças não são estatisticamente significantes $(\mathrm{p}=0,17)$. 
Tabela 1 - Características clínico-laboratoriais das crianças com colestase

\begin{tabular}{|c|c|c|c|c|c|c|c|c|c|c|c|c|}
\hline Ident. & $\begin{array}{l}\text { Idade } \\
\text { (meses) }\end{array}$ & $\begin{array}{l}\text { Peso } \\
\text { (gramas) }\end{array}$ & $\begin{array}{l}\text { Estatura } \\
(\mathrm{cm})\end{array}$ & $\begin{array}{l}\text { Tempo de } \\
\text { colestase } \\
\text { (meses) }\end{array}$ & $\begin{array}{l}\mathbf{A S T} \\
(\mathbf{U} / \mathbf{I})\end{array}$ & $\begin{array}{l}\text { ALT } \\
(\mathbf{U} / \mathbf{I})\end{array}$ & $\begin{array}{l}\text { BT/BD } \\
(\mathrm{mg} / \mathrm{ml})\end{array}$ & $\begin{array}{l}\text { GGT } \\
\text { (U/I) }\end{array}$ & $\begin{array}{l}\text { FA } \\
(\mathbf{U} / \mathbf{I})\end{array}$ & \multicolumn{2}{|c|}{$\begin{array}{l}\text { ALB. VIT. D } \\
\text { (g/dl) (ng/ml) }\end{array}$} & $\begin{array}{l}\text { Doença } \\
\text { de base }\end{array}$ \\
\hline 1 & 9 & 7.020 & 66 & 9 & 191 & 237 & $3,1 / 1,6$ & 317 & 858 & 3,9 & 17,821 & AVBEH \\
\hline 2 & 62 & 19.500 & 105,5 & 62 & 170 & 69 & $16,2 / 7,6$ & 72 & 836 & 2,9 & 10,192 & AVBEH \\
\hline 3 & 10 & 7.900 & 68 & 10 & 224 & 53 & $8,4 / 3,9$ & 53 & 1062 & 2,6 & 11,174 & AVBEH \\
\hline 4 & 156 & $34.200^{\ddagger}$ & $143,5^{\dagger \S}$ & 4 & 154 & 58 & $8,1 / 4,9$ & 850 & 1204 & 3,5 & 15,884 & НCPТ \\
\hline 5 & 21 & 11.300 & 86 & 21 & 137 & 84 & $11,5 / 6,5$ & 130 & 459 & 2,4 & 15,413 & AVBEH \\
\hline 6 & 9 & $6.680^{* \dagger}$ & $67,5^{\S}$ & 9 & 225 & 229 & $14,5 / 7,9$ & 215 & 2,305 & 2,7 & 10,748 & $\mathrm{~S} / \mathrm{D}$ \\
\hline 7 & 167 & 61.500 & 158 & 12 & 338 & 190 & $5,3 / 2,5$ & 33 & 617 & 2,2 & 4,1055 & $\mathrm{~S} / \mathrm{D}$ \\
\hline 8 & 5 & $5.200^{*} \ddagger$ & $60^{\dagger \S}$ & 5 & 152 & 79 & $8,1 / 4,1$ & 440 & 1567 & 2,6 & 7,9937 & AVBEH \\
\hline 9 & 6 & $5.850^{*} \ddagger$ & $62^{\dagger \S}$ & 6 & 105 & 30 & $38 / 19,2$ & 38 & 359 & 3 & 28,115 & Hep Neo \\
\hline 10 & 41 & 16.000 & 93 & 41 & 125 & 72 & $1,6 / 0,7$ & 105 & 1682 & 3,2 & 28,033 & AVBEH \\
\hline 11 & 93 & $17.000^{*}$ * & $110^{\dagger \S}$ & 93 & 83 & 111 & $1,8 / 0,8$ & 341 & 1303 & 4 & 21,007 & S. Alagille \\
\hline 12 & 15 & 9.500 & 73,5 & 15 & 154 & 68 & $29,5 / 22,6$ & 180 & 1205 & 4 & 4,3446 & S.Alagille \\
\hline 13 & 216 & 60.300 & 163 & 104 & 187 & 89 & $3,8 / 2,2$ & 80 & 587 & 2,1 & 6,9592 & FHC \\
\hline 14 & 156 & $30.800^{\ddagger}$ & $136^{\S}$ & 12 & 675 & 417 & $4,7 / 3,5$ & 133 & 946 & 4,4 & 5,2052 & HCAI \\
\hline 15 & 36 & 15.160 & $85^{\dagger \S}$ & 3 & 131 & 115 & $1,6 / 0,8$ & 482 & 996 & 3,8 & 13,631 & AVBEH \\
\hline 16 & 4 & 6.100 & 65 & 4 & 477 & 365 & $17,9 / 9,3$ & 733 & 1935 & 3,5 & 4,7355 & AVBEH \\
\hline 17 & 156 & 55.700 & 156 & 5 & 134 & 144 & $2,9 / 1,0$ & 43 & 698 & 3 & 9,7474 & HCAI \\
\hline 18 & 192 & 77.300 & 176 & 192 & 96 & 119 & $3,2 / 1,3$ & 316 & 737 & 3,6 & 18,601 & AVBEH \\
\hline 19 & 7 & 7.720 & 68 & 7 & 95 & 72 & $7,4 / 4,4$ & 322 & 1236 & 2,7 & 32,662 & AVBEH \\
\hline 20 & 47 & $11.800^{* \ddagger}$ & $91^{\dagger \S}$ & 47 & 212 & 149 & $14,3 / 7,3$ & 100 & 1500 & 4,5 & 3,1203 & S.Alagille \\
\hline 21 & 137 & 30.200 & 151 & 137 & 125 & 115 & $5,0 / 2,5$ & 94 & 745 & 2,5 & 7,3323 & AVBEH \\
\hline 22 & 33 & $12.450^{\ddagger}$ & $87,5^{\dagger \S}$ & 12 & 150 & 208 & $4,6 / 2,5$ & 178 & 3562 & 4 & 10,757 & FHC \\
\hline
\end{tabular}

$\mathrm{AST}=$ aspartaaminoaminotransferase, $\mathrm{ALT}=$ alaninoaminotransferase, $\mathrm{BT} / \mathrm{BD}=$ bilirrubina total/bilirrubina direta, $\mathrm{GGT}=\mathrm{gamaglutamiltransferase}, \mathrm{FA}=\mathrm{fosfatase}$ alcalina, $A l b=$ albumina, Vit $\mathrm{D}=$ vitamina $\mathrm{D}, \mathrm{AVBEH}=$ atresia de vias biliares extra-hepática, $\mathrm{HCPT}=$ hepatite crônica pós-transplante, $\mathrm{S} / \mathrm{D}=\mathrm{sem}$ diagnóstico, $\mathrm{Hep} \mathrm{NeO}=$ hepatite neonatal, S. Alagille= síndrome de Alagille, $\mathrm{FHC}=$ fibrose hepática congênita, $\mathrm{HCAl}=$ hepatite crônica autoimune.

* Peso com mais de 2 desvios padrão de média (escore $z$ ) em relação à idade.

$\dagger$ Estatura com mais de 2 desvios padrão abaixo da média (escore z) em relação à idade.

† Peso com percentil inferior a $5 \mathrm{~m}$ em relação à idade (NCHS).

$\S$ Estatura com percentil inferior a 5 em relação à idade (NCHS).

O valor médio de vitamina $\mathrm{D}$ entre os pacientes colestáticos foi de $13,07 \pm 8,39 \mathrm{ng} / \mathrm{ml}$, e entre os controles foi de $25,58 \pm 16,73 \mathrm{ng} / \mathrm{ml}$. A Figura 1 demonstra que houve diferença estatisticamente significante. Entre os indivíduos colestáticos, observamos uma prevalência de $36 \%$ de déficit de vitamina $\mathrm{D}$ (valores menores de $9 \mathrm{ng} / \mathrm{ml}$ ). Já no grupo controle, não foi constatada deficiência desta vitamina.

A mediana dos valores de vitamina $\mathrm{D}$ nos eutróficos foi de $10,47 \mathrm{ng} / \mathrm{ml}$, e nos desnutridos foi de $13,63 \mathrm{ng} / \mathrm{ml}$, não havendo diferença estatística significativa, como demonstra a Figura 2. A correlação entre o tempo de colestase e os níveis plasmáticos de vitamina $\mathrm{D}$ também não foi significativa, na qual observamos um coeficiente de correlação de Spearmann de $-0,09$, com valor $\mathrm{p}=0,67$.

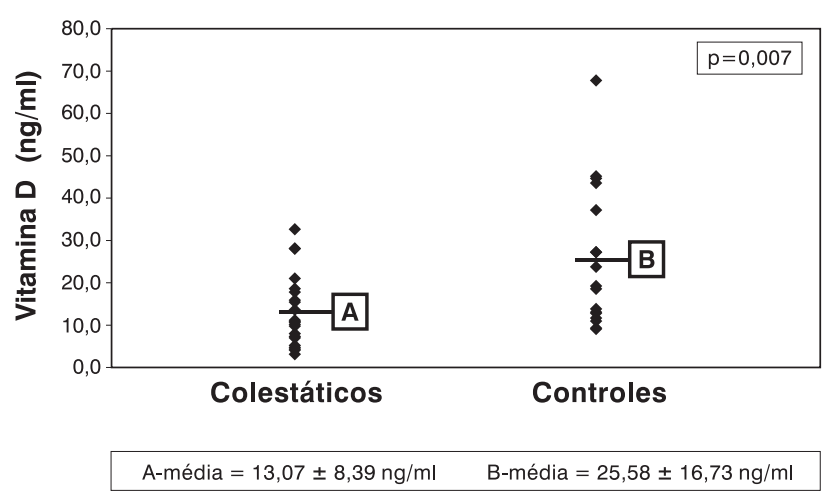

Figura 1 - Níveis plasmáticos de vitamina D (ng/ml) em colestáticos e em controles (teste $t$ paramétrico) 


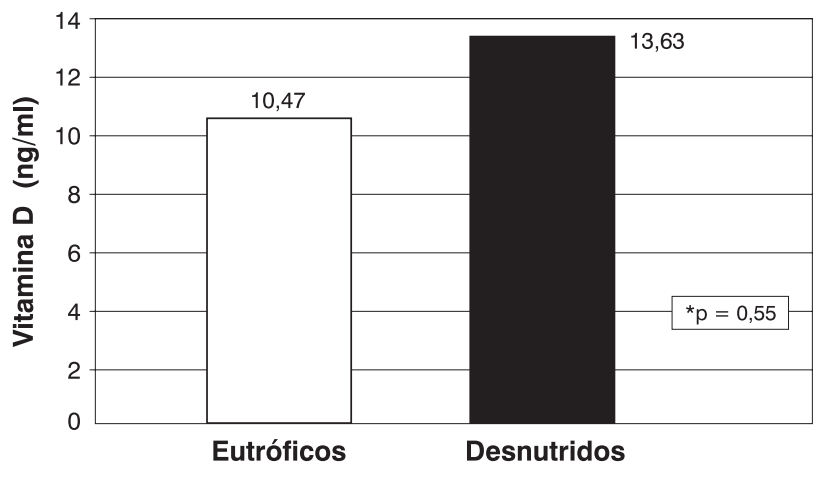

Figura 2 - Níveis plasmáticos de vitamina D (ng/ml) entre pacientes colestáticos, de acordo com o estado nutricional (Mann-Whitney)

Ao compararmos os níveis plasmáticos de vitamina D entre os pacientes que utilizam regularmente a suplementação oral e os que não utilizam tal suplementação, verificamos que não há diferença estatisticamente significante, como demonstra a Figura 3.

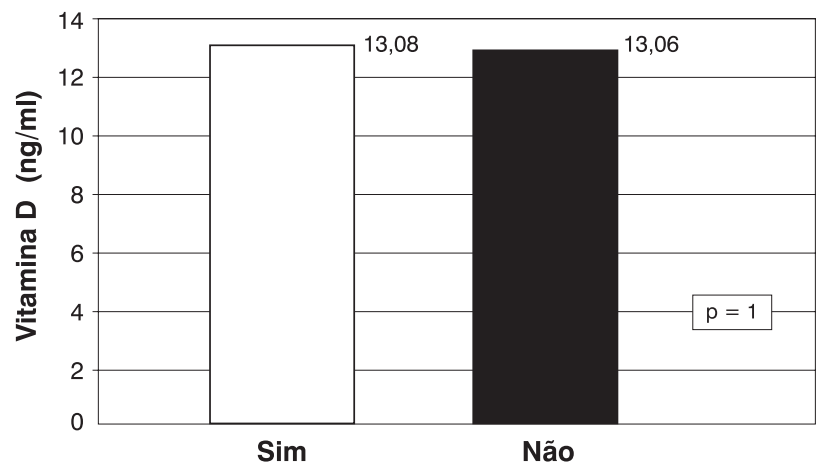

Figura 3 - Comparação das medianas dos níveis plasmáticos de vitamina $\mathrm{D}$ entre pacientes que utilizam ou não suplemento oral (Mann-Whitney U)

\section{Discussão}

As concentrações plasmáticas adequadas da vitamina $\mathrm{D}$ existem na dependência da ingestão da vitamina D2 e D3, e da biossíntese cutânea da vitamina D3, após exposição à luz ultravioleta. A absorção depende do fluxo biliar adequado, e ocorre ao nível do jejuno e do íleo, onde é transportada como quilomícrons até o fígado. Neste órgão, é submetida à 25-hidroxilação, transformando-se em 25 OHD. Após, a 25OHD retorna à circulação e será transportada até o rim, onde será submetida 1a hidroxilação, para formar 1,25 dihidroxivitamina $\mathrm{D}\left[1,25\left(\mathrm{OH}_{2}\right) \mathrm{D}\right]$, ou 24,25 dihidroxivitamina D [24,25 $\left.\left(\mathrm{OH}_{2}\right) \mathrm{D}\right]$, na dependência do estado de suficiência de vitamina $\mathrm{D}^{14}$. A secreção do paratormônio (PTH) estimula a síntese de $1,25\left(\mathrm{OH}_{2}\right) \mathrm{D} 3$ no rim, que promoverá a mobilização de cálcio do osso e intestino e regulará a síntese do próprio $\mathrm{PTH}$, por retroação negativa. A 25(OH)D é a forma da vitamina que se encontra circulante em maior quantidade, enquanto que a $1,25\left(\mathrm{OH}_{2}\right) \mathrm{D}$ é a forma ativa da vitamina ${ }^{7}$.

Estudos que avaliam os níveis plasmáticos de vitamina $\mathrm{D}$ em crianças e adolescentes com hepatopatia crônica são demonstrados na Tabela 2. Heubi e colaboradores ${ }^{10}$ dosaram os níveis plasmáticos de vitamina $\mathrm{D}$, após dose teste da vitamina em crianças com colestase, e os compararam com crianças sem colestase, observando significativa má absorção no primeiro grupo. Bucuvalas e colaboradores ${ }^{15}$, avaliando a absorção de cálcio e níveis plasmáticos de vitamina D em crianças com hepatopatia crônica, concluem que outros fatores devem contribuir para a redução da massa óssea nestes pacientes, já que os níveis de vitamina D e cálcio encontravam-se normais na maioria dos pacientes colestáticos estudados. Lembramos que foi estudada uma amostra de apenas nove indivíduos. Estudo tailandês ${ }^{16}$ sobre densidade óssea e 25OHD, em pacientes com atresia de vias biliares, verificou que os níveis de 25OHD eram significativamente menores entre o grupo com colestase do que no grupo sem colestase. No presente estudo, observamos valores de vitamina $D$ significativamente menores entre os colestáticos, quando comparado a crianças normais (Figura 1).

Chin e colaboradores ${ }^{17}$, avaliando diversos aspectos da desnutrição em pacientes com hepatopatia crônica, encontraram uma prevalência de $25 \%$ de hipovitaminose D no grupo de hepatopatas crônicos, sem distinguir a ocorrência de colestase. Já Argao e colaboradores ${ }^{18}$ verificaram uma prevalência de $29 \%$ de hipovitaminose D entre crianças com colestase crônica. O presente estudo encontrou deficiência de vitamina $\mathrm{D}$ em $36 \%$ dos pacientes com colestase.

Em relação ao ponto de corte utilizado em nosso estudo para considerar hipovitaminose $\mathrm{D}(9 \mathrm{ng} / \mathrm{ml})$, esse foi baseado nos valores informados pelos fornecedores do kit 25hidroxyvitamin D - Nichols Institute Diagnostics - Paris. $\mathrm{O}$ mesmo foi feito no estudo de Pugliesi et al. ${ }^{19}$, que também usou a técnica de radioimunoensaio na avaliação de crianças sem hepatopatia. Chin e colaboradores ${ }^{17} \mathrm{e}$ Argao e colaboradores ${ }^{18}$, citados anteriormente, utilizaram a técnica de HPLC, considerando baixos os valores menores que $15 \mathrm{ng} / \mathrm{ml}$ (Tabela 2 ).

A constatação de desnutrição, verificada tanto pelos percentis do NCHS como pelo escore z, foi em torno de 30$40 \%$, sendo semelhante à observada em estudos realizados em Porto Alegre ${ }^{11,20}$. Porém há relatos na literatura nos quais a prevalência de desnutrição em hepatopatas pode 
Tabela 2 - Estudos que avaliam níveis plasmáticos de vitamina D em crianças e adolescentes com hepatopatia crônica

\begin{tabular}{|c|c|c|c|c|c|}
\hline Autor (ano) & Delineamento & $\begin{array}{l}\text { Amostra } \\
\mathbf{N}=*\end{array}$ & $\begin{array}{l}\text { Faixa } \\
\text { etária }\end{array}$ & $\begin{array}{l}\text { Técnica } \\
\text { utilizada }\end{array}$ & Observações \\
\hline $\begin{array}{l}\text { Heubi et al. }{ }^{9} \\
(1989)\end{array}$ & $\begin{array}{l}\text { Transversal } \\
\text { controlado } \\
\text { com intervenção }\end{array}$ & $\begin{array}{l}\text { Hepatopatas crônicos } \\
\text { com colestase. } \mathrm{N}=6 \\
\text { Controles com outras } \\
\text { doenças sem hepatopatia. } \\
\mathrm{N}=6\end{array}$ & 1 a 19 anos & $\mathrm{CBPA}^{\dagger}$ & $\begin{array}{l}\text { Medidas de } 25(\mathrm{OH}) \mathrm{D} \\
\text { após dose teste de vitamina } \mathrm{D} \text { : } \\
\text { má absorção nos colestáticos }\end{array}$ \\
\hline $\begin{array}{l}\text { Bucuvalas et al. }{ }^{14} \\
(1990)\end{array}$ & $\begin{array}{l}\text { Transversal } \\
\text { controlado }\end{array}$ & $\begin{array}{l}\text { Hepatopatas crônicos } \\
\text { com colestase. } \mathrm{N}=9 \\
\text { Hepatopatas crônicos } \\
\text { sem colestase. } \mathrm{N}=5\end{array}$ & $4 \mathrm{~m}$ a 16 anos & $\mathrm{CBPA}^{\dagger}$ & $\begin{array}{l}\text { Baixos níveis de vitamina D } \\
\text { em } 1 \text { dos } 9 \text { colestáticos }\end{array}$ \\
\hline $\begin{array}{l}\text { Chin et al. }{ }^{16} \\
\text { (1992) }\end{array}$ & Transversal & $\begin{array}{l}\text { Hepatopatas crônicos } \\
\mathrm{N}=27\end{array}$ & $6 \mathrm{~m}$ a 6 anos & HPLC ${ }^{\ddagger}$ & $\begin{array}{l}\text { Hipovitaminose D: } \\
25 \% \text { dos pacientes }\end{array}$ \\
\hline $\begin{array}{l}\text { Argao et al. }{ }^{17} \\
(1993)\end{array}$ & Transversal & $\begin{array}{l}\text { Hepatopatas crônicos } \\
\text { com colestase. } \mathrm{N}=56\end{array}$ & $2 \mathrm{~m}$ a 20 anos & HPLC $\ddagger$ & $\begin{array}{l}\text { Hipovitaminose D: } \\
29 \% \text { dos pacientes }\end{array}$ \\
\hline $\begin{array}{l}\text { Chongsrisawat et al. }{ }^{15} \\
(2001)\end{array}$ & Transversal & $\begin{array}{l}\text { Portadores de AVBEH } \\
\mathrm{N}=42\end{array}$ & $6 \mathrm{~m}$ a 10 anos & RIE $\S$ & $\begin{array}{l}\text { Vitamina D significativamente } \\
\text { menor nos colestáticos }\end{array}$ \\
\hline $\begin{array}{l}\text { Presente estudo } \\
(\mathbf{2 0 0 2 )}\end{array}$ & $\begin{array}{l}\text { Transversal } \\
\text { controlado }\end{array}$ & $\begin{array}{l}\text { Hepatopatas crônicos } \\
\text { com colestase. } \mathrm{N}=22 \\
\text { Controles normais. } \mathrm{N}=17\end{array}$ & $4 \mathrm{~m}$ a 18 anos & $\mathrm{RIE}^{\S}$ & $\begin{array}{l}\text { Vitamina D significativamente } \\
\text { menor nos colestáticos } \\
\text { Hipovitaminose D: } \\
36 \% \text { dos pacientes }\end{array}$ \\
\hline
\end{tabular}

* número de indivíduos, ${ }^{\dagger}$ Competitive Protein Binding Assay, ${ }^{\ddagger}$ High Pressure Liquid Cromatography, $§$ Radioimunoensaio.

chegar a $70 \%^{3}$. Em uma população sadia, se encontra menos de $1 \%$ de déficits graves, e cerca de $2,3 \%$ de déficits $\operatorname{moderados}^{21}$.

Para avaliar a relação do estado nutricional com as demais variáveis estudadas, utilizou-se o escore $\mathrm{z}$ altura/ idade. A relação dos pacientes eutróficos e desnutridos com o tempo de colestase e os níveis plasmáticos de vitamina D não evidenciou diferenças estatisticamente significativas. O fato da mediana dos níveis plasmáticos de vitamina D apresentar-se mais baixa entre os colestáticos eutróficos (Figura 2) não pode ser valorizado, por não apresentar significância estatística, e também porque os estudos que realizaram a mesma comparação não observaram relação significativa entre estado nutricional e níveis plasmáticos de vitamina $\mathrm{D}^{17,18}$.

Observamos que a hipovitaminose D ocorreu independentemente do uso do suplemento oral prescrito. Ao compararmos a mediana dos níveis plasmáticos de vitamina $\mathrm{D}$ entre os pacientes que usavam suplemento oral e os que não usavam, não obtivemos diferenças, como demonstra a Figura 3. Nos estudos relatados na Tabela 2, a referência ao uso de suplemento oral de vitamina D é feita apenas por Heubi et al. ${ }^{10}$ e Bucuvalas et al. ${ }^{15}$, com doses de 2.500 a
50.000 UI/dia. No nosso meio, utilizamos a apresentação comercial Aderogyl D3, 12 gotas, 2x dia, que equivale a aproximadamente $26.000 \mathrm{UI} /$ dia de colecalciferol e 66.000 $\mathrm{UI} /$ dia de acetato de retinol. A recomendação mais recente ${ }^{2}$ é de monitorização periódica dos níveis plasmáticos de 25OH-D associada à adequada exposição solar, e uma dieta normal em quantidades de cálcio e fósforo. Se houver deficiência de vitamina $\mathrm{D}$, utilizar vitamina D3 oral, três a dez vezes a recomendação para idade; $25 \mathrm{OHD}$ (Calderol ${ }^{\circledR}$ ) 3 a $5 \mathrm{mg} / \mathrm{kg} / \mathrm{dia}$; ou 1,25 (OH)2D (Rocaltrol $\left.{ }^{\circledR}\right), 0,05$ a $0,2 \mathrm{mg} / \mathrm{kg} / \mathrm{dia}$. Durante o uso destas vitaminas, deve haver monitorização cuidadosa dos seus níveis plasmáticos.

A utilização de doses maiores de vitamina D3 ou o uso de 1,25(OH2)D (Rocaltrol $\left.{ }^{\circledR}\right)$ é viável, porém apresenta riscos de intoxicação, para o que se recomenda uma monitorização cuidadosa. Esse fato, associado à prevalência de hipovitaminose encontrada entre os pacientes avaliados neste estudo, reforça a importância de introduzir a dosagem plasmática de vitamina $\mathrm{D}$ nos protocolos de investigação, e o acompanhamento dos pacientes colestáticos do nosso meio.

A prevalência de osteopenia não fez parte dos objetivos do nosso estudo, mas sabemos que está relacionada com a 
deficiência de vitamina $\mathrm{D}$. Vieira ${ }^{11}$ realizou densitometria óssea em 20 pacientes com colestase crônica atendidos no HCPA, com idades entre três a dezoito anos, e observou que todos apresentavam diminuição da massa óssea total. Apesar da osteopenia estar relacionada com colestase crônica em crianças, sua patogênese não está claramente definida. Alguns autores não conseguiram relacionar os níveis plasmáticos de vitamina $D$ com densidade óssea ${ }^{14,18}$. Já Chongrisawat e colaboradores ${ }^{16}$ compararam a densidade óssea mineral com níveis plasmáticos de $25 \mathrm{OHD}$ em crianças colestáticas, e constataram que pacientes com osteoporose apresentavam menores valores de vitamina D. Portanto, a deficiência de vitamina $\mathrm{D}$ não é a única determinante da doença metabólica óssea em crianças e adultos colestáticos, mas sua deficiência pode ser corrigida e, assim, prevenir um dos fatores que contribuem para esta morbidade.

Concluímos que a média dos níveis plasmáticos de vitamina $D$ nas crianças e adolescentes colestáticos avaliados foi significativamente menor do que em crianças e adolescentes normais. Encontramos uma prevalência de hipovitaminose $\mathrm{D}$ de $36 \%$ entre os pacientes colestáticos estudados. Não observamos relação entre os níveis plasmáticos de vitamina D e o estado nutricional, o tempo de colestase ou o uso regular de suplementação vitamínica. Portanto, recomendamos a monitorização dos níveis plasmáticos de vitamina $\mathrm{D}$ em pacientes colestáticos, a fim de detectar as deficiências e poder monitorizar uma suplementação mais efetiva.

\section{Agradecimentos}

Ao chefe do laboratório de radioimunoensaio do Hospital de Clínicas de Porto Alegre, Dr. José Romildo de Jesus, e à bioquímica do mesmo laboratório, Dra. Ligia Crossetti, pelo apoio técnico na realização das dosagens plasmáticas de vitamina $\mathrm{D}$.

À nutricionista Carla Rosane Silveira, pela colaboração ao realizar avaliação antropométrica dos pacientes da pesquisa.

\section{Referências bibliográficas}

1. Erlinger S. Medical management of chronic cholestasis. In: Schiff E, Sorrel MM, Mandrey WC, editores. Schiff's Diseases of the liver. $8^{\mathrm{a}}$ ed. Filadélfia: Lippincoot-Raven Publishers; 1999.p.611-29.
2. Feranchak AP, Ramires RO, Sokol RJ. Medical and nutritional management of cholestasis. In: Suchy FJ, Sokol RJ, Balistreri F, editores. Liver disease in children. Filadélfia: Lippincott Williams \& Wilkins; 2001.p.195-237.

3. Cabêdo MTC. Terapia nutricional em situações especiais: insuficiência hepática. In: Falcão MC, Carazza FR. Manual Básico de Apoio Nutricional em Pediatria. São Paulo: Atheneu; 1999.p.99-106.

4. Sherlock S, Dooley J. Diseases of the liver and biliary system. $10^{\mathrm{a}}$ ed. Oxford: Blackwell Science; 1997.

5. Mahan LK, Stump ES, editores. Krause - Alimento, Nutrição e Dietoterapia. 9a ed. São Paulo: Roca; 1998.

6. Clemens TL, Adams JS. Vitamin D and metabolites. In: Favus MJ, editor. Primer on the metabolic bone diseases and disorders of mineral metabolism. $2^{a}$ ed. New York: Raven; 1993.p.103-12.

7. Hollick M. Vitamina D. In: Nóbrega FJ, editor. Distúrbios da Nutrição. Rio de Janeiro: Revinter; 1998.p.339-45.

8. Hollis BW, Kamerud JQ, Selvaag SR, Lorenz JD, Napoli JL. Determination of vitamin $\mathrm{D}$ status by radioimmunoassay with an ${ }^{125}$ I-labeled tracer. Clin Chem 1993;39:529-33.

9. Hollis BW. Comparison of commercially available ${ }^{125} \mathrm{I}$-based RIE methods for determination of circulating 25-Hydroxyvitamin D. Clin Chem 2000;46:1657-61.

10. Heubi JE, Hollis BW, Specker B, Tsang RC. Bone disease in chronic childhood cholestasis. I. Vitamin D absorption and metabolism. Hepatology 1989;9:258-64.

11. Vieira SMG. Densidometria óssea e fosfatasemia alcalina esquelética em crianças e adolescentes com colestase crônica [dissertação]. Porto Alegre (RS): Universidade Federal do Rio Grande do Sul; 1995.

12. NCHS - National Center for Health Statistic - World Health Organization. Growth Curves for Children, Birth - 18 years. Washington(DC): Department of Health, Education and Welfare; 1997.

13. WHO Expert Committee on Physical Status: The Use And Interpretation of Anthropometry. Geneva: WHOTechnical Report Series: 854; 1995.

14. Norman AW, Henry LH. Vitamin D: metabolism and mechanism of action. In: Favus MJ, editor. Primer on the metabolic bone diseases and disorders of mineral metabolism. $2^{\mathrm{a}}$ ed. New York: Raven; 1993.p.63-70.

15. Bucuvalas JC, Heubi JE, Specker BL, Gregg DJ, Yergey AL, Vieira NE. Calcium absorption in bone disease associated with chronic cholestasis during childhood. Hepatology 1990;12: 1200-5.

16. Chongsrisawat V, Rottanamongkol P, Chaiwatanarat $\mathrm{T}$, Chandrakamol B, Poovorawan Y. Bone density and 25hydroxyvitamin D level in extrahepatic biliary atresia. Pediatr Surg Int 2001;17:604-8.

17. Chin SE, Shepherd RW, Thomas BJ, Cleghorn GJ, Patrick MK, Wilcox JA, et al. The nature of malnutrition in children with endstage liver disease awaiting orthotopic liver transplantation. Am J Clin Nutr 1992;56:164-8.

18. Argao EA, Specker BL, Heubi JE. Bone mineral content in infants and children with chronic cholestatic liver disease. Pediatrics 1993;91(6):1151-4.

19. Pugliese MT, Blumberg DL, Hludzinski J, Kay S. Nutritional rickets in suburbia. J Am Coll Nutr 1998;17:637-41. 
20. Gazal CHA. O Inquérito nutricional, antropometria e avaliação da absorção intestinal de proteínas e gorduras pela dosagem de alfa-1-antitripsina fecal e do esteatócrito na avaliação nutricional de crianças com cirrose [dissertação]. Porto Alegre (RS): Universidade Federal do Rio Grande do Sul; 1995.

21. Ministério da Saúde. Metas Governamentais para o ano 2000. Brasília: Ministério da Saúde; 1996.
Endereço para correspondência:

Dra. Marília Dornelles Bastos

Rua Fernando Abott, 391/ 204

CEP 96810-150 - Santa Cruz do Sul, RS

E-mail:mariliabastos@viavale.com.br 